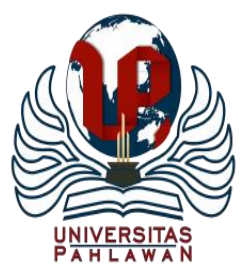

Jurnal Basicedu Volume 5 Nomor 1 Tahun 2021 Halaman 301-309

JURNAL BASICEDU

Research \&Learning in Elementary Education

https://jbasic.org/index.php/basicedu

\title{
Perbedaan Model Problem Based Learning dengan Discovery Learning Terhadap Higher Order Thinking Skills dan Self Directed Learning Di Sekolah Dasar
}

\author{
Friska Efendi ${ }^{1}$, Yanti Fitria ${ }^{2}$, Farida $\mathrm{F}^{3}$, Hadiyanto ${ }^{4}$ \\ Program Studi Pendidikan Dasar, Universitas Negeri Padang, Indonesia 1,2,3,4 \\ E-mail: $\underline{\text { friskaefendi96@gmail.com }}^{1}$ yanti_fitria@fip.unp.ac.id ${ }^{2} \underline{\text { faridafachrudin6@ gmail.com }}^{3}$ \\ hadiyanto@fip.unp.ac.id ${ }^{4}$
}

\begin{abstract}
Abstrak
Penelitian ini bertujuan untuk mengetahui adanya perbedaan yang signifikan terhadap Higher Order Thinking Skills (HOTS) menggunakan model Problem Based Learning (PBL) dan yang menggunakan model Discovery Learning (DL) terhadap Self Directed Learning pada pembelajaran tematik terpadu Kelas V di SD Negeri 03 Sintuak Toboh Gadang. Jenis penelitian ini adalah penelitian eksperimen dengan desain quasi exsperimental dengan bentuk non equivalent control group design. Teknik sampel yang digunakan yaitu teknik purposive sampling dengan berdasarkan hasil normalitas dan homogenitas maka terpilihlah SDN 03 Sintuak Toboh Gadang dengan sampel yang terdiri dari dua kelas, yaitu kelas eksperimen I kelas V.A menggunakan model Problem Based Learning yang berjumlah 24 peserta didik dan kelas eksperimen II kelas V.B menggunakan model Discovery Learning yang berjumlah 24 peserta didik. Hasil penelitian terlihat bahwa hasil uji-t diperoleh $\mathrm{t}_{\text {hitung }}-3,6<\mathrm{t}_{\text {tabel }}$ 1,7 maka $\mathrm{H}_{\mathrm{o}}$ diterima. Dengan demikian dapat disimpulkan bahwa terdapat perbedaan yang signifikan penggunaan model Problem Based Learning dengan Discovery Learning terhadap High Order Thinking Skills dan Self Directed Learning di kelas V Sekolah Dasar.
\end{abstract}

Kata kunci : problem based learning, discovery learning, higher order thinking skills

Abstract

This study aims to determine whether there are significant differences in HOTS models Problem Based Learning (PBL) and which uses the Discovery Learning (DL) to Self Directed Learning model integrated thematic learning in class V SD Negeri 03 Sintuak Toboh Gadang. This type of research is an experimental research with a Quasi-experimental design in the form of a non-equivalent control group design. The sample technique used was purposive sampling technique based on the results of normality and homogeneity, so SDN 03 Sintuak Toboh Gadang was chosen with a sample consisting of two classes, namely the experimental class I class VA using the Problem Based Learning model totaling 24 students and experimental class II class VB using the Discovery Learning model, amounting to 24 students. The research results show that the results uji$t$ obtained thitung $-3,6<t_{\text {tabel }}$ 1,7 then $H_{o}$ be accepted. Thus it can be concluded that there is a significant difference in the use of the Problem Based Learning model with Discovery Learning on High Order Thinking Skills and Self Directed Learning in grade V Elementary School.

Keywords : problem based learning, discovery learning, higher order thinking skills

Copyright (c) 2021 Friska Efendi, Yanti Fitria, Farida F, Hadiyanto

$\triangle$ Corresponding author

Address : Universitas Negeri Padang

Email : friskaefendi96@gmail.com

ISSN 2580-3735 (Media Cetak)

DOI: https://doi.org/10.31004/basicedu.v5i1.647

ISSN 2580-1147 (Media Online) 
302 Perbedaan Model Problem Bassed Learning dengan Discovery Learning terhadap Higher Order Thingking Skills dan Self Directed Learning di Sekolah Dasar- Friska Efendi, Yanti Fitria, Farida F, Hadiyanto

DOI: https://doi.org/10.31004/basicedu.v5i1.647

\section{PENDAHULUAN}

Pendidikan mempunyai peranan yang sangat penting dalam menentukan perkembangan suatu negara. Pendidikan di Indonesia terus berkembang dalam segala bidang. Salah satunya dengan adanya perubahan dibidang program pendidikan yaitu Kurikulum 2013. Kurikulum 2013 diharapkan mampu membangun karakter peserta didik sehingga dapat diimplementasikan dalam kehidupan sehari-hari mereka. Agar terjadinya peningkatan dan keseimbangan antara konsepsi sikap (attitude), keterampilan (skill), dan pengetahuan (knowledge). Hal itu sejalan dengan (Kemendikbud, 2018) yaitu pencapaian pada kurikulum 2013 mencakup sikap, pengetahuan, dan keterampilan sesuai dengan standar nasional yang telah ditentukan.

$$
\text { Pada perencanaan pembelajaran }
$$

Kurikulum 2013 mengutamakan pembelajaran tematik terpadu (Fitria Y, 2019). Makna terpadu dalam pembelajaran adalah keterkaitan antara beberapa kompetensi dasar (KD) suatu mata pelajaran yang dilahirkan satu atau beberapa tema pembelajaran. Muatan di dalam tematik terpadu terdiri dari mata pelajaran Bahasa Indonesia, Matematika, IPS, IPA, PPKn, dan, SBdP.

Proses pembelajaran di kelas dilaksanakan untuk memperkuat pendekatan ilmiah (scientific). Permendikbud 22 tahun 2018 mengamanatkan bahwa pelaksanaan pembelajaran di SD dapat diperkuat dengan menggunakan model Problem
Based Learning (PBL) dan Discovery Learning (DL).

PBL merupakan suatu model pembelajaran yang bercirikan adanya permasalah nyata dimana peserta didik dilibatkan untuk memecahkan masalah sebagai dasar dalam pengembangan pengetahuan baru peserta didik melalui tahaptahap ilmiah (Moutinho et al., 2015). Tujuan utama dari model PBL adalah pengembangan kemampuan belajar sendiri, keterampilan penyelidikan dan kemampuan pemecahan masalah, sekaligus kemampuan peserta didik yang secara aktif membangun pengetahuannya sendiri (Farisi et al., 2017).

Discovery Learning (DL) merupakan model pembelajaran untuk menemukan konsep melalui pengamatan atau percobaan. Hal ini sejalan dengan pendapat (Sani, 2015) bahwa DL merupakan model pembelajaran yang mengikutsertakan peserta didik untuk menemukan sebuah konsep untuk mengatasi permasalahan di dunia nyata melalui serangkaian informasi yang diperoleh dengan pengamatan atau percobaan, sehingga peserta didik mampu menyelesaikan masalah dan membuat keputusan. Tujuan pembelajaraan berbasis penemuan ialah agar peserta didik mampu mencari dan menemukan sebuah konsep sendiri (Hahdi, 2018).

High Order Thinking Skills mendorong peserta didik untuk menyelesaikan suatu permasalahan, sehingga peserta didik mampu menganalisis permasalahan, memikirkan pilihan solusi, menerapkan strategi masalah serta 
303 Perbedaan Model Problem Bassed Learning dengan Discovery Learning terhadap Higher Order Thingking Skills dan Self Directed Learning di Sekolah Dasar- Friska Efendi, Yanti Fitria, Farida F, Hadiyanto

DOI: https://doi.org/10.31004/basicedu.v5i1.647

mengevaluasi solusi yang diterapkan. Hal ini sejalan dengan pernyataan (Budiarta et al., 2018) High Order Thinking Skills merupakan proses berpikir yang mempersiapkan peserta didik untuk menyelesaikan permasalahan dalam kehidupan sehari-hari, sehingga peserta didik memiliki pemahaman konsep yang mendalam tentang sebuah ide untuk menerapkan pengetahuan untuk memecahkan permasalahan.

Pada pembelajaran Kurikulum 2013 berorientasi pada HOTS dengan pembelajaran berbasis masalah serta evaluasi pembelajaran yang dipersiapkan untuk peserta didik terlatih menjawab soal-soal pada level lebih tinggi. Hal ini bertujuan agar keterampilan berpikir tingkat tinggi dikuasai dan diterapkan pada proses pembelajaran sehingga peserta didik terbiasa memecahkan permasalahan yang sulit. Dan dapat menemukan hal-hal baru dalam menghadapi perubahan zaman (Widodo et al., 2019).

Self Directed Learning merupakan suatu kemampuan yang dimiliki oleh peserta didik untuk dapat berpikir, merencanakan, memilih strategi, dan mengevaluasi kemandirian belajarnya sehingga peserta didik tersebut dapat menyelesaikan masalah secara efektif. Self Directed Learning mendorong seseorang untuk peningkatan kemauan dan keterampilan peserta didik dalam proses belajar tanpa bantuan orang lain. Hal ini sesuai dengan pernyataan (Siagian et al., 2020) melalui pembelajaran mandiri, peserta didik akan meningkatkan kemampuan belajarnya mulai dari tingkat yang paling sederhana sampai pada merencanakan, mengendalikan dan menilai sendiri hasil belajarnya. Karena kemandirian belajar merupakan salah satu penentu keberhasilan peserta didik dalam proses pembelajaran.

Dari tingkat sekolah dasar peserta didik harusnya sudah dibekali kemandirian belajar agar mampu mengembangkan potensi yang dimilikinya (Fitria Y, 2017). Oleh karena itu pendidik harus membekali peserta didik dengan cara memberikan banyak pengalaman belajar dan memberikan contoh positif saat proses pembelajaran berlangsung.

Berdasarkan hasil studi pendahuluan yang peneliti lakukan di SDN 03 Sintuak Toboh Gadang ditemukan bahwa selama proses pembelajaran pendidik menjelaskan materi mengenai siklus air dan peserta didik menyimak materi yang disampaikan. Lalu, peserta didik diminta untuk mencatat siklus air ke dalam buku catatannya dan tahap selanjutnya pendidik memberikan latihan. Dan pada saat pendidik memberikan latihan sebagian besar peserta didik bertanya kepada teman, serta banyak siswa yang kurang percaya diri mengerjakan tugasnya. Selain itu, pada kegitan akhir pembelajaran saat peserta didik ditanya siklus air mereka sering terbolak balik memberikan penjelasan. Sehingga, berdampak juga terhadap rendahnya kemampuan berpikir tingkat tinggi peserta didik.

Bersumber pada permasalahan di atas, maka peneliti melakukan penelitian yang berjudul "Perbedaan Model Problem Based Learning dengan Discovery Learning terhadap 
304 Perbedaan Model Problem Bassed Learning dengan Discovery Learning terhadap Higher Order Thingking Skills dan Self Directed Learning di Sekolah Dasar- Friska Efendi, Yanti Fitria, Farida F, Hadiyanto

DOI: https://doi.org/10.31004/basicedu.v5i1.647

High Order Thinking Skills dan Self Directed Learning di Kelas V Sekolah Dasar".

\section{METODE}

Penelitian ini menggunakan jenis penelitian kuantitatif. Metode penelitian yang digunakan adalah penelitian eksperimen. (Sugiyono, 2013) menyatakan bahwa penelitian eksperimen dapat dinyatakan sebagai metode penelitian yang digunakan untuk mencari perbandingan perlakuan tertentu terhadap yang lain dalam kondisi yang terkendali. Desain penelitian ini adalah quasi eskperimental design. Peneliti menggunakan pretest-posttest control group design. Pada desain ini kelompok eksperimen I maupun kelompok eksperimen II tidak dipilih secara random. Penelitian ini dilaksanakan di SDN 03 Sintuak Toboh Gadang pada bulan Februari tahun 2020.

Populasi dalam penelitian ini adalah seluruh kelas V SDN Gugus I Sintuak Toboh Gadang Kabupaten Padangparaiaman. Teknik pengambilan sampel adalah purposive sampling.

Peneliti memilih sampel berdasarkan kriteria yang telah dipilih oleh peneliti. Sampel tersebut pilih karena, 1) kurikulumnya menggunakan kurikulum 2013, 2) kelas yang digunakan adalah kelas paralel, 3) kedua kelas memiliki jumlah siswa yang sama. Berdasarkan kriteria yang telah dipilih oleh peneliti maka terpilihlah 5 SD yang memakai K.13. Tetapi yang menggunakan kelas paralel, dan jumlah siswa pada SDN 03 Sintuak Toboh Gadang dan SDN 08 Sintuak Toboh Gadang. Dan SD yang terpilih adalah SDN 03 Sintuak Toboh Gadang jumlah siswanya 48 orang yaitu di kelas V.A 24 siswa dan di kelas V.B 24 siswa. Setelah itu dilakukan uji prasyarat dan didapat hasil bahwa kedua kelas pada SD tersebut memiliki kelas yang nomal dan homogen.

\section{HASIL DAN PEMBAHASAN}

Penelitian dilakukan terhadap dua kelas, yaitu kelas V.A sebanyak 24 orang sebagai kelas eksperimen I dengan cara memberi perlakuan yaitu menerapakan model PBL dan sebagai kelas eksperimen II kelas V.B sebanyak 24 orang yang yaitu menerapakan model DL. Sebelum peneliti melakukan proses pembelajaran peserta didik pada kelas eksperimen I dan kelas eksperimen II diberi soal pretest untuk mengetahui kemampuan awal peserta didik. Selanjutnya, peneliti melakukan proses pembelajaran, lalu setelah proses pembelajaran peserta didik diberikan soal posttest untuk mengetahui kemampuan peserta didik setelah proses pembelajaran.

Sebelum soal pretest dan postest diberikan kepada peserta didik, soal-soal tersebut telah diujicobakan di sekolah lain yang memiliki karakter yang sama dengan sekolah tempat penelitian. Setelah dilakukan uji coba soal, data yang didapatkan di analisis validitas, reliabilitas, tingkat kesukaran dan daya beda soal. Data yang telah dianalisis itulah yang diberikan kepada kelas eksperimen I dan kelas eksperimen II. Berikut ini hasil tes HOTS posttest peserta didik pada kelas eksperimen I dan kelas eksperimen II. 
305 Perbedaan Model Problem Bassed Learning dengan Discovery Learning terhadap Higher Order Thingking Skills dan Self Directed Learning di Sekolah Dasar- Friska Efendi, Yanti Fitria, Farida F, Hadiyanto

DOI: https://doi.org/10.31004/basicedu.v5i1.647

Tabel 1. Data Statistik Skor HOTS (Pretest) Kelas V.A dan Kelas V.B

\begin{tabular}{|c|c|c|}
\hline \multirow{2}{*}{ Data Statistik } & \multicolumn{2}{|c|}{ Pretest } \\
\cline { 2 - 3 } & Kelas V.A & Kelas V.B \\
\hline Nilai Tertinggi & 66,67 & 73,08 \\
\hline Nilai terendah & 22,22 & 30,77 \\
\hline Rata-rata & 40,509 & 51,76 \\
\hline Standar Deviasi & 12,949 & 12,1615 \\
\hline Varians & 167,682 & 147,9022 \\
\hline Jumlah siswa & 24 & 24 \\
\hline
\end{tabular}

Berdasarkan tabel 1 di atas didapatkan hasil tes HOTS pretest kedua kelas menunjukkan perbedaan. Nilai maksimum pretest yang diperoleh di kelas yang diajar menggunakan model PBL lebih tinggi daripada nilai maksimum di kelas yang diajar menggunakan model DL yaitu 73,08 dan 66,67. Selain itu, nilai rata-rata kedua kelas juga menunjukan perbedaan yaitu 51,76 untuk nilai rata-rata model PBL dan 40,509 untuk nilai rata-rata model DL dan selisih nilai rata-rata kedua kelas ialah sebesar 11,251. Dari hasil tersebut terlihat bahwa perolehan nilai pretest kelas model PBL lebih tinggi dari pada kelas model D L .

Tabel 2. Data Statistik Skor HOTS (Posttest) Kelas V.A dan Kelas V.B

\begin{tabular}{|c|c|c|}
\hline \multirow{2}{*}{ Data Statistik } & \multicolumn{2}{|c|}{ Pretest } \\
\cline { 2 - 3 } & Kelas V.A & Kelas V.B \\
\hline Nilai Tertinggi & 88,46 & 94,44 \\
\hline Nilai terendah & 46,15 & 44,44 \\
\hline Rata-rata & 72,76 & 68,357 \\
\hline Standar Deviasi & 10,87364 & 17,907 \\
\hline Varians & 118,236 & 320,671 \\
\hline $\begin{array}{c}\text { Jumlah } \\
\text { siswa }\end{array}$ & 24 & 24 \\
\hline
\end{tabular}

Berdasarkan tabel 2 di atas didapatkan hasil tes HOTS pretest kedua kelas menunjukkan perbedaan. Nilai maksimum pretest yang diperoleh di kelas yang diajar menggunakan model PBL lebih tinggi dari nilai maksimum di kelas yang diajar menggunakan model DL yaitu 94,44 dan 88,46 . Selain itu, nilai rata-rata kedua kelas juga menunjukan perbedaan yaitu 68,357 nilai rata-rata model PBL dan 72,76 nilai ratarata model DL dan selisih nilai rata-rata kedua kelas ialah sebesar 4,403. Dari hasil tersebut terlihat bahwa perolehan nilai posttest kelas model PBL lebih tinggi dari pada kelas model DL.

Setelah itu data diolah dengan uji hipotesis. Sebelum uji hipotesis harus dilakukan beberapa uji prasyarat terhadap data hasil tes HOTS. Uji normalitas untuk membuktikan bahwa kedua sampel berdistribusi normal. Hasil perhitungan yang didapatkan dari uji normalitas disajikan pada tabel berikut.

\section{Tabel 3. Hasil Uji Normalitas Pretest}

\begin{tabular}{|c|l|l|c|c|}
\hline Variabel & \multicolumn{1}{|c|}{ Kelas } & Lhitung & L tabel & Kesimpulan \\
\hline \multirow{2}{*}{$\begin{array}{c}\text { HOTS } \\
\text { Pretest }\end{array}$} & $\begin{array}{l}\text { Model } \\
\text { PBL }\end{array}$ & 0,169 & 0,173 & Normal \\
\cline { 2 - 3 } & $\begin{array}{l}\text { Model } \\
\text { DL }\end{array}$ & 0,155 & & \\
\hline
\end{tabular}

Dari tabel data hasil pengujian normalitas yang telah dilakukan menggunakan uji Liliefors pada kelas model PBL menunjukkan Lhitung<Ltabel yaitu: $0,169<0,173$. Sementara pada kelas model DL menunjukkan Lhitung $<$ Ltabel yaitu: $0,155<0,173$. Kedua kelas sampel terdistribusi normal. Setelah uji normalitas hasil pretest, selanjutnya dilakukan uji normalitas pada hasil posttest. 
306 Perbedaan Model Problem Bassed Learning dengan Discovery Learning terhadap Higher Order Thingking Skills dan Self Directed Learning di Sekolah Dasar- Friska Efendi, Yanti Fitria, Farida F, Hadiyanto

DOI: https://doi.org/10.31004/basicedu.v5i1.647

Tabel 4. Hasil Uji Normalitas Postest

\begin{tabular}{|c|l|c|c|c|}
\hline Variabel & Kelas & Lhitung & $\mathbf{L}_{\text {tabel }}$ & Kesimpulan \\
\hline $\begin{array}{c}\text { HOTS } \\
\text { Postest }\end{array}$ & $\begin{array}{l}\text { Model } \\
\text { PBL }\end{array}$ & 0,138 & 0,173 & Normal \\
\cline { 2 - 3 } & $\begin{array}{l}\text { Model } \\
\text { DL }\end{array}$ & 0,144 & & \\
\hline
\end{tabular}

Berdasarkan tabel data hasil pengujian normalitas yang menggunakan uji Liliefors pada kelas model PBL menunjukkan Lhitung <Ltabel yaitu: $0,138<0,173$. Sedangkan pada kelas model DL menunjukkan Lhitung<Ltabel yaitu: $0,144<0,173$. Kedua kelas sampel terdistribusi normal. Selanjutnya dilakukan uji homogenitas pada hasil tes HOTS pretest dan postest.

Tabel 5. Hasil Uji Homogenitas

\begin{tabular}{|c|c|c|c|c|}
\hline $\begin{array}{c}\text { Kelompok } \\
\text { Uji }\end{array}$ & $\boldsymbol{\alpha}^{\mathbf{2}}$ & $\mathbf{h}_{\text {hitung }}$ & $\mathbf{h}_{\text {tabel }}$ & Kesimpulan \\
\hline HOTS & 0,05 & 0,00184 & 4,17 & Homogen \\
siswa yang & & & & \\
memiliki & & & & \\
Self & & & & \\
Directed & & & & \\
Learning & & & & \\
Model PBL & & & & \\
dan Model & & & & \\
DL & & & & \\
\hline
\end{tabular}

Berdasarkan tabel 5 terlihat bahwa hasil tes HOTS mempunyai nilai b-hitung lebih besar dari b-tabel pada taraf nyata $(\alpha=0,05)$. Hal ini berarti terima Ho dan dapat disimpulkan bahwa data HOTS peserta didik yang memiliki Self Directed Learning di kelas eksperimen I dan kelas eksperimen II bervarians homogen.

Tabel 6. Hasil Uji Hipotesis Pertama

\begin{tabular}{|l|c|c|c|c|c|c|c|}
\hline Kelas & $\mathbf{N}$ & $\mathbf{S}_{\mathbf{g a b}}$ & $\boldsymbol{a}$ & $\mathbf{D k}$ & $\mathbf{t}_{\text {hitung }}$ & $\mathbf{t}_{\text {tabel }}$ & Keterangan \\
\hline PBL & 12 & 0,97 & 0,05 & 22 & $-3,6$ & 1,7 & $\mathrm{H}_{0}$ Diterima \\
\hline DL & 12 & & & & & & \\
\hline
\end{tabular}

Berdasarkan tabel 6 terlihat bahwa hasil uji$\mathrm{t}$ penghitungan $\mathrm{n}$ _gain pada kelas yang diajar dengan model PBL dan DL diperoleh harga thitung $-3,6<$ ttabel 1,7 maka Ho diterima yaitu terdapat perbedaan HOTS peserta didik pada tema 6 subtema 3 menggunakan Model PBL dengan model DL.

Tabel 7. Hasil Uji Hipotesis Kedua

\begin{tabular}{|l|c|c|c|c|c|c|c|}
\hline Kelas & $\mathbf{N}$ & $\mathbf{S}_{\text {gab }}$ & $\boldsymbol{\alpha}$ & $\mathbf{D k}$ & $\mathbf{t}_{\text {titung }}$ & $\mathbf{t}_{\text {tabel }}$ & Keterangan \\
\hline PBL & 12 & 0,89 & 0,05 & 22 & 0,26 & 1,79 & $\mathrm{H}_{0}$ Diterima \\
\cline { 1 - 2 } DL & 12 & & & & & & \\
\hline
\end{tabular}

Berdasarkan tabel 7 hasil uji-t penghitungan n_gain pada kelas yang diajar dengan model PBL dan DL diperoleh harga thitung $0,26<$ ttabel 1,79 maka Ho diterima yaitu terdapat perbedaan HOTS peserta didik pada tema 6 subtema 3 yang memiliki Self Directed Learning tinggi menggunakan Model PBL dan Model DL.

Tabel 8. Hasil Uji Hipotesis Ketiga

\begin{tabular}{|c|c|c|c|c|c|c|c|}
\hline Kelas & $\mathbf{N}$ & $\mathbf{S}_{\text {gab }}$ & $\boldsymbol{\alpha}$ & $\mathbf{D k}$ & $\mathbf{t}_{\text {hitung }}$ & $\mathbf{t}_{\text {tabel }}$ & Keterangan \\
\hline PBL & 12 & 0,87 & 0,05 & 22 & $-16,7$ & 1,89 & $\mathrm{H}_{0}$ Diterima \\
\cline { 1 - 2 } DL & 12 & & & & & & \\
\hline
\end{tabular}

Berdasarkan tabel 8 hasil uji-t penghitungan n_gain pada kelas yang diajar dengan model PBL dan DL didapatkan $t_{\text {hitung }}$ $16,7<\mathrm{t}_{\text {tabel }} 1,89$ maka $\mathrm{H}_{\mathrm{o}}$ diterima yaitu terdapat perbedaan HOTS peserta didik pada tema 6 
307 Perbedaan Model Problem Bassed Learning dengan Discovery Learning terhadap Higher Order Thingking Skills dan Self Directed Learning di Sekolah Dasar- Friska Efendi, Yanti Fitria, Farida F, Hadiyanto

DOI: https://doi.org/10.31004/basicedu.v5i1.647

subtema 3 yang memiliki Self Directed Learning rendah menggunakan Model DL.

Tabel 9. Hasil Uji Hipotesis Keempat

\begin{tabular}{|c|c|c|c|c|c|}
\hline Sumber Varians & $d k$ & SS & MS & $F_{\text {hitung }}$ & $F_{\text {tabel }}$ \\
\hline Baris (A) & 1 & 272,284 & 272,284 & 4,04 & \multirow[t]{5}{*}{4,26} \\
\hline Baris (B) & 1 & 7907,43 & 3953,72 & 3,19 & \\
\hline Interaksi (AB) & 1 & 945157 & 472579 & 9,08 & \\
\hline Dalam Sel & 48 & 2186006 & 52047,8 & & \\
\hline Total & 51 & 3139343 & & & \\
\hline
\end{tabular}

Pada tabel 9 berdasarkan hasil penghitungan anava dua arah di atas, dapat disimpulkan bahwa :

1. Pada baris (A) $F_{\text {hitung }}<F_{\text {tabel }}$, maka $H_{o}$ diterima sehingga dapat disimpulkan bahwa pada taraf kepercayaan $95 \%$ terdapat perbedaan HOTS peserta didik menggunakan Model PBL dengan Model DL.

2. Pada baris (B) $F_{\text {hitung }}<\mathrm{F}_{\text {tabel }}$, Maka $\mathrm{H}_{\mathrm{o}}$ diterima sehingga dapat disimpulkan bahwa pada taraf kepercayaan $95 \%$ terdapat perbedaan antara HOTS peserta didik yang memiliki Self Directed Learning lebih tinggi dengan menggunakan Model PBl daripada Model DL.

3. Pada baris (AB) $F_{\text {hitung }}>F_{\text {tabel}}$, maka $\mathrm{H}_{\mathrm{o}}$ ditolak sehingga dapat disimpulkan bahwa pada taraf kepercayaan 95\% tidak terdapat interaksi antara antara Model PBL dengan Model DL terhadap HOTS dalam mempengaruhi Self Directed Learning peserta didik.

Sebelum penelitian, peneliti membuat perencanaan yang matang yaitu membuat
Rencana Pelaksanaan Pembelajaran (RPP) kurikulum 2013 dengan memasukkan kegiatan pembelajaran yang menggunakan langkahlangkah model PBL dan DL. Menyiapkan lembar kerja peserta didik serta alat dan bahan yang akan digunakan pada tema 6 (Panas dan Perpindahannya) Subtema 3 (Pengaruh kalor terhadap kehidupan) Pembelajaran 1 dan 2. Dan melakukan pretest untuk melihat kemampuan awal peserta didik. Serta mempersiapkan angket Self Directed Learning.

Peneliti menggunakan langkah model pembelajaran yang dijelaskan oleh (Sani, 2015) yaitu (1) memberikan orientasi permasalahan kepada siswa, (2) mengorganisasikan siswa untuk penyelidikan, (3) pelaksanaan investigasi, (4) mengembangkan dan menyajikan hasil, (5) menganalisis dan mengevaluasi proses penyelidikan.

Pada saat penelitian dilakukan, peneliti membuka kegiatan pembelajaran dengan bertanya jawab, persepsi, membangkitkan semangat dan mengkondisikan kelas. Setelah peserta didik siap untuk mengikuti pembelajaran, peneliti mengawali kegiatan dengan menarik peserta didik pada masalah keseharian.

Selanjutnya kegiatan inti pembelajaran, kemudian peserta didik diberi tugas dalam LKPD agar menemukan solusi dari permasalahan yang sudah disajikan dengan berdiskusi dan tanya jawab serta penyajian hasil. Kemudian sebagai bentuk apresiasi peneliti terhadap peserta didik, peneliti memberikan tepuk tangan untuk peserta didik yang berani mengemukakan pendapatnya 
308 Perbedaan Model Problem Bassed Learning dengan Discovery Learning terhadap Higher Order Thingking Skills dan Self Directed Learning di Sekolah Dasar- Friska Efendi, Yanti Fitria, Farida F, Hadiyanto

DOI: https://doi.org/10.31004/basicedu.v5i1.647

serta hadiah untuk menghargai usaha peserta didik.

Pada pembelajaran dikelas eksperimen II, peneliti menggunakan model Discovery Learning peneliti menggunakan langkah model pembelajaran yang dijelaskan oleh (Carin \& Sund, 1993) yaitu (1) menjelaskan tujuan/ mempersiapkan peserta didik, (2) orientasi peserta didik pada masalah, (3) melakukan kegiatan penemuan (4) mempresentasikan hasil kegiatan penemuan, (5) mengevaluasi kegiatan penemuan.

Selanjutnya kegiatan inti pembelajaran, peserta didik diberi penugasan agar bisa melakukan menemukan, yang dilakukan dengan berdiskusi dan tanya jawab serta penyajian hasil diskusi. Untuk memberikam penguatan terhadap peserta didik, peneliti memberikan tepuk tangan untuk peserta didik yang telah berani mengemukakan pendapatnya.

Setelah melaksanakan pembelajaran pada kelas eksperimen I dan eksperimen II, dilanjutkan dengan pemberian tes akhir kepada peserta didik berupa soal pilihan ganda yang berjumlah 18 soal HOTS. Dari tes akhir tersebut diperoleh rata-rata hasil tes aspek pengetahuan kelas eksperimen I dan II dengan menggunakan model PBL dan DL.

Selanjutnya peneliti memberikan angket Self Directed Learning kepada masing-masing peserta didik di kelas eksperimen I dan di kelas eksperimen I. Angket tersebut diberikan untuk mengetahui perbedaan Self Directed Learning peserta didik.

\section{SIMPULAN}

Simpulan berdasarkan hasil analisis data adalah terdapat perbedaan HOTS peserta didik pada tema 6 subtema 3 menggunakan Model PBL dengan model DL. Hal ini ditunjukkan dari perolehan hasil perhitungan uji hipotesis posttest melalui uji-t pada taraf signifikansi 0,05, dimana $t_{\text {hitung }}-3,6<1,7 t_{\text {tabel }}$ maka $H_{o}$ diterima. Model PBL merupakan salah satu model yang sudah dibuktikan dapat memberi pengaruh positif terhadap HOTS peserta didik jika dibandingkan dengan model DL di dalam kelas.

Berdasarkan hasil penelitian yang dilakukan maka dikemukakan saran-saran sebagai berikut: (1) bagi guru kelas V SDN 03 Sintuak Toboh Gadang dapat menerapkan model pembelajaran Problem Based Learning dan Discovery Learning dalam proses pembelajaran, karena terbukti dapat mempengaruhi HOTS peserta didik. (2) Bagi peneliti lanjut, yang ingin melakukan penelitian sejenis hendaknya mengkaji aspek Problem Based Learning dan Discovery Learning dengan variasi yang dapat meningkatkan HOTS peserta didik. Dalam penelitian ini keterpaduan topik masih terbatas pada beberapa topik dari tiga mata pelajaran. Untuk peneliti berikutnya dapat memadukan berbagai topik terkait agar kebermaknaan pembelajaran bagi peserta didik agar lebih baik.

\section{DAFTAR PUSTAKA}

Budiarta, K., Harahap, M. H., \& Mailani, E. (2018). POTRET IMPLEMENTASI PEMBELAJARAN BERBASIS HIGH 
309 Perbedaan Model Problem Bassed Learning dengan Discovery Learning terhadap Higher Order Thingking Skills dan Self Directed Learning di Sekolah Dasar- Friska Efendi, Yanti Fitria, Farida F, Hadiyanto

DOI: https://doi.org/10.31004/basicedu.v5i1.647

ORDER THINKING SKILLS ( HOTS ) DI SEKOLAH DASAR KOTA MEDAN. 6, $102-111$.

Carin, \& Sund. (1993). Theaching Science Through Discover.

Farisi, A., Hamid, A., \& Melvin. (2017). Pengaruh Model Pembelajaran Problem Based Learning Terhadap Kemampuan Berpikir Kritis Dalam Meningkatkan Hasil Belajar Siswa Pada Konsep Suhu Dan Kalor. Jurnal Ilmiah Mahasiswa (JIM) Pendidikan Fisika, 2, 283-287.

Fitria, Y. (2017). Sciencetific Literacy as Foundation in Character Building for Early Chilhood and Elementary Grade School. Advances in SociaL Science, Education and Humanities Research (ASSEHR), 169.

Fitria, Y. (2019). Landasan Pembelajaran Sains Terintergrasi (Terpadu) Untuk Level Dasar. Sukabina Press.

Hahdi, D. S. (2018). Eksperimentasi Model Problem Based Learning dan Guided Discovery Learning Terhadap Kemampuan Pemecahan Masalah Matematis ditinjau dari Self Efficacy Siswa. Jurnal Cakrawala Pendas, 4(1).

Kemendikbud. (2018). Permendikbud no 22 Peraturan Menteri Pendidikan dan Kebudayaan tentang Standar Proses Pendidikan Dasar dan Menengah. Kemendikbud.

Moutinho, S., Torres, J., Fernandes, I., \& Vasconcelos, C. (2015). Problem-Based Learning And Nature of Science: A Study With Science Teachers. Procedia - Social and Behavioral Sciences, 191, 1871-1875. https://doi.org/10.1016/j.sbspro.2015.04.32 4

Sani, R. A. (2015). Pembelajaran Saintifik Untuk Implementasi Kurikulum 2013. Bumi Aksara.

Siagian, H., Pangaribuan, J. J., \& Silaban, P. J. (2020). Pengaruh Kemandirisn Belajar Terhadap Hasil Belajar Matematika Siswa di Sekolah Dasar. Basic Education, 4, 1363-1369.

Sugiyono. (2013). Metode Penelitian Kuantitatif, Kualitatif dan $R \& D$. Alfabeta.

Widodo, A., Indraswati, D., Radiusman, Usman, \& Nursaptini. (2019). Analisis Konten HOTS dalam buku Siswa Kelas V Tema 6 "Panas dan Perpindahannya" Kurikulum 2013. Pendidikan Dan Pembelajaran Dasar, 12, 1. 